\title{
Da Formação à Prática: Experiências de Duas Professoras Sobre as Investigações Estatísticas no Envolvimento do Aluno
}

\section{From Training to Practice: Experiences of Two Teachers in Statistical Investigations in Student Engagement}

\author{
Bruna Mayara Batista Rodrigues ; João Pedro Mendes da Ponte*a
}

anstituto de Educação, Universidade de Lisboa, Programa de Pós-Graduação Stricto Sensu em Educação. Portugal.

*E-mail: jpponte@ie.ulisboa.pt.

\begin{abstract}
Resumo
Investigações estatísticas, como tarefas a propor aos alunos, são uma poderosa ferramenta de ensino, promovendo a aprendizagem significativa dos conceitos e representações estatísticas. Esta atividade permite integrar o aluno ao processo estatístico, fazendo-o ver além dos dados, mesmo com conhecimentos estatísticos relativamente básicos. Este estudo busca analisar como professores de Matemática conduzem as investigações estatísticas, nomeadamente no que se refere aos seguintes aspectos relacionados ao envolvimento do aluno na escola: capacidade de motivar os alunos; o plano de aula; e a gestão de sala de aula. A investigação tem por base dois estudos de caso de professoras de Matemática participantes numa experiência de formação, num curso de especialização. A recolha de dados inclui gravações de áudio e vídeo das sessões relacionadas com as investigações e relatórios escritos das investigações, e a análise de dados é realizada segundo as etapas do ciclo que compõe uma investigação estatística. Os resultados mostram que as professoras, em seu planejamento, consideram que as investigações estatísticas permitem motivar os alunos a aprender a partir de temas relacionados com a própria realidade. No que se refere à gestão da aula, as professoras privilegiam a comunicação dos alunos. Os resultados sugerem a necessidade de um maior destaque deste assunto nos processos de formação de professores, de modo que eles experimentem atividades desta natureza e ganhem confiança para poder conduzir as diferentes etapas do ciclo investigativo no trabalho com os seus alunos.
\end{abstract}

Palavras-chave: Ensino da Estatística. Investigações Estatísticas. Formação De Professores. Envolvimento do Aluno.

\begin{abstract}
Statistical investigations, as tasks to propose to the students, constitute a powerful teaching tool, promoting meaningful learning of the statistical concepts and representations. This activity allows integrating students in the statistical process, by making them see beyond data, even with basic statistical knowledge. This study seeks to analyze how mathematics teachers conduct statistical investigations, namely regarding the following aspects related to student involvement in school: the ability to motivate students, the teaching plan, and the classroom management. This research is based in two case studies of mathematics teachers who participated in a teacher education experience, in a specialization course. Data collection includes audio and video recording of the investigations-related sessions and data analysis is carried out according to the statistical investigation cycle. The results show that the teachers consider the statistical investigations in their planning are efficient to motivate the students to learn with themes related to their own reality. With regard to class management, teachers prioritize student communication. The results suggest the need for greater emphasis on this issue in teacher education processes, so that they themselves experience activities of this nature and gain confidence to conduct the different stages of the investigation cycle in the school context.
\end{abstract}

Keywords: Statistics education. Statistical Investigations. Teacher Education. Student Engagement.

\section{Introdução}

As informações estatísticas estão presentes nas mais diversas áreas, como a economia, medicina, política e educação. A Estatística é a ciência que trata de dados e tem um papel importante na vida escolar dos alunos, desde os níveis de escolaridade mais elementares, para que eles possam desenvolver competências para lidar com informação de forma crítica e bem articulada. Martins e Ponte (2011) afirmam que "Tal como foi importante para os nossos avós aprenderem a ler e contar, hoje em dia, a educação para a cidadania inclui saber ler e interpretar os números e gráficos com que nos deparamos no dia-a-dia" (p. 7).

A inclusão de conteúdos relacionados com a Estatística no currículo é relativamente recente. No Brasil, somente em 1997, após a publicação dos Parâmetros Curriculares
Nacionais (PCN), os tópicos de Estatística surgiram nas orientações para o ensino da Matemática, nomeadamente no bloco "Tratamento da Informação", um dos quatro blocos que compõem os PCNs no Ensino Fundamental. No Ensino Médio, estes tópicos foram inseridos no eixo "Análise de Dados". Diante desta inclusão tardia, os professores enfrentam desafios ao lecionar este tema. Em primeiro lugar, os conceitos estatísticos devem ser trabalhados de modo distinto das outras áreas da Matemática como a Geometria ou a Álgebra. Isto se dá por que a variabilidade é inerente aos processos estatísticos, enquanto as outras áreas de Matemática possuem características deterministas. Em segundo lugar, existe um problema fulcral na formação inicial dos professores de Matemática nas disciplinas de Estatística, pois, em muitos casos, existe apenas um trabalho voltado para a Estatística 
Descritiva, sem a devida discussão dos aspectos didáticos que permeiam este ensino.

Deste modo, há uma insegurança nas ações do professor que prejudica o envolvimento do aluno nas tarefas relacionadas à Estatística. Por consequência, esta é abordada no contexto escolar com o direcionamento à reprodução de exercícios para a fixação dos conceitos. De acordo com Bahia, Veiga e Galvão (2014), este ensino inibe a criatividade do aluno, o que dificulta a sua aprendizagem ativa e, consequentemente, afeta os seus aspectos motivacionais. Deste modo, é necessário pensar numa abordagem exploratória da Estatística, em que o ciclo investigativo assume um lugar importante.

No presente artigo $^{1}$ estudamos os casos de duas professoras de Matemática participantes numa experiência de formação, especificamente num curso de especialização para professores de Matemática. Buscamos analisar o modo como conduzem imvestigações estatísticas em sala de aula com atenção aos seguintes elementos relacionados com o papel do professor no envolvimento dos alunos na escola: plano de aula; gestão de sala de aula; e capacidade de motivar os alunos.

\section{Enquadramento Teórico}

\subsection{O envolvimento do aluno na escola e a formação de professores}

O envolvimento do aluno na escola constitui um importante conceito a se ter em conta no ensino-aprendizagem. De acordo com Veiga et al. (2012), este envolvimento tem caráter multidimensional e emerge da articulação das dimensões acadêmica, comportamental, cognitiva e psicológica. Para Bahia et al. (2014), o envolvimento dos alunos salienta-se na "cultura da própria escola" e o desempenho está associado ao desenvolvimento da autonomia e à aprendizagem, cujo centro é o aluno. Barkley (2010), por sua vez, inclui a motivação como um elemento essencial para o envolvimento dos alunos na escola, que deve ser articulada à aprendizagem ativa do aluno.

Diante das particularidades inerentes ao envolvimento dos alunos na escola é necessário pensar nos aspectos relacionados ao papel do professor neste processo, visto que é este quem promove a mediação das ações em sala de aula e é quem propõe as tarefas nas quais os alunos poderão raciocinar, comunicar ideias, interagir e criar estratégias de solução. Ou seja, ainda que seja um processo vivenciado pelo aluno, o seu envolvimento consiste numa coconstrução exercida no contexto escolar de modo global. O professor, em especial, deve criar um ambiente favorável para isso, por meio dos recursos a serem utilizados e dos conteúdos a serem trabalhados (Hipkins, 2012). Para Skinner e Pitzer (2012), as relações estabelecidas entre o professor e o aluno são fundamentais para que o aluno esteja motivado com as atividades inerentes ao contexto escolar.

Veiga et al. (2012) afirmam que, no processo de envolvimento do aluno na escola, é necessário que os professores detenham fortes competências para ensinar. Isto inclui a competência na matéria que ensinam, na medida em que têm conhecimentos teóricos e sabem fazer conexões entre diferentes ideias e conceitos, além da competência de estabelecer estratégias de ensino e adaptar tarefas e abordagens de acordo com as necessidades dos alunos.

Ainda no que diz respeito ao conhecimento profissional do professor, os autores destacam a planificação do ensino e a gestão da sala de aula como competências essenciais ao professor no envolvimento dos alunos na escola. Neste sentido, o plano de ensino, ou, mais especificamente, o plano de aula, refere-se à seleção e organização de um conjunto de aprendizagens a serem alcançadas, cuja seleção deve basear-se nas necessidades e interesses dos alunos (Posner \& Rudnitsky, 2006). A gestão da sala de aula, por sua vez, deve ter como foco a criação de um ambiente positivo de aprendizagem. Assim, os professores devem criar estratégias para organizar a turma, lidar com as diferentes interações e, principalmente, promover o envolvimento dos alunos com as diferentes tarefas que lhes são propostas. Embora o foco na gestão da sala de aula deva ser a aprendizagem, em muitos casos, o trabalho do professor é direcionado à manutenção da ordem em sala de aula, de modo que as dimensões psicológica e comportamental acabam por receber maior destaque do que a dimensão cognitiva (Cothran \& Ennis, 2000).

Veiga et al. (2012) ainda fazem referência a outras competências necessárias aos professores que não são, necessariamente, específicas do conhecimento profissional do professor. Estas habilidades são: a capacidade de motivação dos alunos; a comunicação interpessoal; a consideração das diferenças individuais; a avaliação de desempenho; e a utilização de novas tecnologias. De acordo com os autores, “cada uma destas competências é assumida como um elemento fundamental na capacitação do professor para promover o envolvimento dos alunos na escola - à semelhança de um rio que engrossa com seus afluentes" (Veiga et al., 2012. p. 38). Os autores ainda enfatizam a influência que os professores podem ter no estímulo ao envolvimento dos alunos na escola, que defendem dever ser encarada como um tema de trabalho nos processos formativos do professor.

De acordo com Smith (2001), a formação de professores deve ser baseada na prática docente. A autora propõe, por exemplo, o uso de tarefas e episódios de sala de aula como oportunidades para a crítica e a observação, em que os professores refletem e constroem conhecimentos. Para Ponte (2011), o trabalho colaborativo também deve fazer parte da formação de professores. Além disto, as tarefas utilizadas devem melhorar o discurso de sala de aula e auxiliar na criação

1 Este trabalho foi apresentado e discutido em sua forma reduzida no III Congresso Internacional Envolvimento dos Alunos na Escola: Perspetivas da Psicologia e Educação, Lisboa. 
de ambientes de aprendizagem que incentivem o raciocínio. $\mathrm{O}$ autor ainda afirma que a formação deve ser capaz de reconhecer e capacitar os professores, levando em conta o seu contexto de trabalho, bem como questões culturais, recursos, regulamentos, diretrizes do sistema de ensino, calendário, além da realidade dos seus alunos, escola e comunidade.

No que diz respeito à formação dos professores para ensinarem Estatística, Heaton e Michelson (2002) apontam as potencialidades da realização de investigações estatísticas, visto que a integração da Estatística no currículo do ensino básico é uma tarefa difícil e que gera mais problemas no ensino-aprendizagem do que o esperado. Assim, a sua proposta é que os conhecimentos de conteúdo e didático dos professores sejam desenvolvidos a partir da realização de investigações estatísticas com os alunos. Neste contexto, a inserção da Estatística no currículo tem por objetivo auxiliar os alunos a conduzirem a formulação de perguntas, coleta e uso de dados com clareza e capacidade para a resolução de problemas.

\subsection{Gestão de tarefas e as investigações estatísticas}

De acordo com Ponte, Quaresma, Mata-Pereira \& Baptista (2015), o conceito de tarefa é muito importante quando o papel ativo do aluno é valorizado, por ser elemento organizador da atividade. Deste modo, perceber o envolvimento dos alunos na escola como um processo cuja participação do professor é fundamental requer refletir sobre os tipos de tarefa que os professores selecionam e o modo como conduzem a sua realização na sala de aula.

Veiga et al. (2012) afirmam que, "ao considerar o envolvimento dos alunos na escola, apela-se a uma metodologia de ensino com práticas interrogativas, que partem do levantamento de questões ou problemas, e apelam a uma maior ação e procura ativa de informação da parte dos alunos" (p. 38). Para os autores, é importante que os alunos sejam estimulados a confrontar problemas associados ao seu contexto de modo a desenvolver o senso crítico. Esta ideia, no âmbito do ensino da Estatística, é divulgada através da realização de investigações estatísticas. Tal como afirma Ponte (2005), as investigações, de modo geral, exigem que os alunos façam planejamento acerca do trabalho a ser desenvolvido, resultando num processo de maior complexidade e desafio. No entanto, de acordo com o autor, selecionar boas tarefas não é o suficiente para que a aprendizagem seja garantida. A condução das tarefas e a maneira com que elas são propostas são de extrema importância para a realização das aulas de Matemática.

O Guidelines for Assessment and Instruction in Statistics Education (GAISE) Report (Franklin et al., 2005) indica que o desenvolvimento da literacia estatística dos alunos é o objetivo final do ensino da Estatística. Este relatório refere que os processos de coleta, exploração e interpretação de dados devem ser direcionados com o intuito de desenvolver a literacia estatística, que, por sua vez, se apresenta como um elemento essencial na tomada de decisões e escolhas pessoais diárias. Um cidadão estatisticamente letrado tende a lidar melhor com as informações do cotidiano, assim como com questões relacionadas ao trabalho. Por este motivo, um ensino centrado em uso de fórmulas e cálculos sem relação com dados reais não é adequado - pelo contrário, a realização das investigações estatísticas deve receber destaque.

Acerca das investigações estatísticas, a estrutura proposta no GAISE Report (Franklin et al., 2005) refere quatro etapas principais: (i) formulação de perguntas; (ii) coleta de dados; (iii) análise de dados; e (iv) interpretação de resultados. Para Kader e Perry (1994), é necessária ainda a inclusão de um quinto componente que se relaciona com a comunicação de resultados. Seguindo esta perspectiva, Friel, Bright, Frierson e Kader (1997) sistematizam as etapas de uma investigação estatística (Figura 1).

Figura 1 - Etapas de uma Investigação Estatística

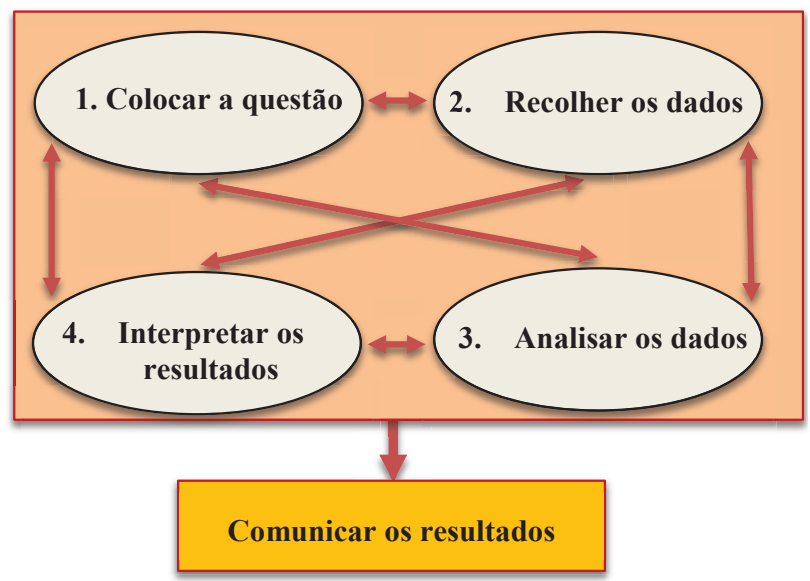

Fonte: Friel et al. (1997).

Martins e Ponte (2011) afirmam que ao longo destas etapas é possível explorar aspectos do raciocínio estatístico, assim como conhecimentos sobre técnicas de recolha de dados, medidas estatísticas de localização, dispersão e associação. Ao realizar esta atividade, o aluno não tem acesso a um conhecimento estatístico sofisticado tal como são as investigações para os estatísticos. No entanto, mesmo com conhecimentos limitados por parte do aluno, a investigação estatística pode ter para ele muito valor. Burrill e Biehler (2011) afirmam que, ao longo de toda a escolaridade, as noções de variabilidade se fazem presentes. Considerando esta ideia como essencial, Makar e Rubim (2007) assumem que a inferência e a investigação estatística são indissociáveis, devendo as investigações serem conduzidas por questões convincentes incluídas num contexto atraente para os alunos. Com isso, é necessária a atenção à produção de dados suficientes para servir de base à discussão e ao processo inferencial.

Além de explorar o raciocínio, a capacidade de organização e de interpretação de dados, as investigações estatísticas propiciam a compreensão de diversos conceitos e representações dentro de contextos reais e acessíveis aos 
alunos. O acesso aos diferentes conceitos e representações deve ser acompanhado de uma exploração crítica da adequação das representações a diferentes situações. Para Martins e Ponte (2011), os alunos, orientados pelo professor, devem planejar a recolha dos dados essenciais para solucionar suas questões a partir de projetos de investigação. A seguir, os dados devem ser tratados e, a partir deste tratamento, os alunos encontrarão respostas e, assim sendo, poderão surgir novas questões.

No Brasil, a Base Nacional Comum Curricular (BNCC), 2017, também orienta para um trabalho que envolva a coleta e a organização de dados de uma investigação que contemple o interesse dos alunos. De acordo com o documento, esta inclusão deve ser progressiva em toda a abordagem da Estatística. Neste sentido, a leitura, interpretação de dados e o uso das representações gráficas assumem um papel importante no ciclo investigativo.

\section{Metodologia}

A investigação que deu origem a este artigo segue uma abordagem qualitativa de cunho interpretativo (Bogdan \& Biklen, 1994), enquadrando-se numa experiência de ensino na modalidade de experiência de formação. Este estudo faz parte de uma investigação de doutorado realizado no Instituto de Educação da Universidade de Lisboa, de modo que a sua realização foi aprovada pela Comissão de Ética da mesma instituição.

A formação enquadra-se num curso de especialização para professores de Matemática que lecionavam, em sua maioria, no Ensino Fundamental na Zona Oeste do Rio de Janeiro, Brasil. Com a articulação entre o conteúdo e a didática da Estatística, a formação caracterizou-se pelo uso de situações autênticas de sala de aula nas diferentes tarefas que os professores realizaram (Smith, 2001). No que diz respeito às investigações estatísticas, puderam experimentar o ciclo investigativo, fazer planejamentos e aplicar na sala de aula com os seus alunos, de modo a retornarem com suas experiências para discussão no âmbito da formação.

Neste artigo estudamos dois casos de professoras cujos nomes fictícios são Cláudia e Luísa, ambas professoras experientes em lecionar Matemática. No decorrer da experiência de formação, tanto uma como outra apresentaram um forte conhecimento do currículo. $\mathrm{Na}$ condição de participantes, mostravam dedicação às atividades propostas e grande intenção em incorporar as aprendizagens às suas práticas. Ambas relataram que não haviam experimentado a realização de investigações estatísticas em sua formação inicial e, consequentemente, não as integravam em suas aulas.

A recolha de dados decorreu da gravação de áudio e vídeo das sessões na experiência de formação, nomeadamente nas duas sessões relacionadas às investigações estatísticas, além da recolha documental dos relatórios produzidos pelas professoras. A partir dos dados recolhidos, realizamos uma análise de conteúdo através de três fases: pré-análise; exploração do material empírico; e tratamento dos resultados, inferências e interpretação (Bardin, 1977). Inicialmente, definimos as categorias de análise, que são baseadas nos componentes do papel do professor no envolvimento dos alunos na escola, apontados por Veiga et al. (2012), com atenção à planificação do ensino, à gestão de sala de aula e à motivação do aluno. No segundo momento, foram definidas as unidades de análise de cada categoria com base nas concepções sobre as investigações estatísticas e o desenvolvimento da literacia estatística destacados por Franklin et al. (2015). Deste modo, seguimos o seguinte quadro para a análise:

Quadro 1 - Categorias de análise

\begin{tabular}{|l|l|}
\hline Categorias & \multicolumn{1}{|c|}{ Unidades de análise } \\
\hline Plano de aula & $\begin{array}{l}\text { - Aprendizagens estatísticas que as professoras } \\
\text { buscam que os seus alunos possam alcançar. } \\
\text { - Papel da literacia estatística no planeamento } \\
\text { da investigação estatística. }\end{array}$ \\
\hline $\begin{array}{l}\text { Gestão de sala } \\
\text { de aula }\end{array}$ & $\begin{array}{l}\text { - Estratégias para conduzir o ciclo investigativo. } \\
\text { - Objetivos para o tipo de organização } \\
\text { estabelecida nas etapas da investigação. }\end{array}$ \\
\hline $\begin{array}{l}\text { Motivação do } \\
\text { aluno }\end{array}$ & $\begin{array}{l}\text { - Elementos da investigação que percepcionam } \\
\text { serem capazes de motivar os alunos. } \\
\text { - Estratégias para motivar os alunos no ciclo } \\
\text { investigativo. }\end{array}$ \\
\hline
\end{tabular}

Fonte: os autores)

\section{Resultados}

A seguir, apresentamos os resultados da pesquisa. Organizamos os resultados de modo a descrever o perfil das professoras, bem como as suas narrativas sobre as etapas da investigação estatística realizada com os seus alunos.

\subsection{Cláudia}

\section{A professora}

Cláudia - uma professora de 39 anos de idade e 19 anos de experiência no ensino - diz ter escolhido a Educação por "pensar que podia mudar o mundo" (Sessão de formação). No decorrer da experiência de formação foi uma participante muito ativa e colaboradora. No trabalho de investigação realizado nas sessões, apresentava conhecimentos sobre os diferentes conceitos estatísticos. Além disto, demonstrou grande interesse pelas potencialidades educativas da realização de investigações estatísticas em sala de aula. Sendo uma professora com bastante experiência em lecionar Matemática, afirma o quanto gosta daquilo que faz. Apesar da quantidade de alunos em sala, que ultrapassa os 40 , percebe a importância da sua função em promover a aprendizagem destes educandos. Além disso, considera-se uma professora exigente, porque sabe que "se deixar muito solto, eles não aprendem" (Sessão de formação). Afirma que é uma professora que gosta de conversar com os seus alunos e de entender os seus diferentes contextos, mas também indica que a disciplina e a organização em sala de aula são fatores muito importantes para a aprendizagem.

Colocar a questão e recolher os dados, Cláudia, como todos os outros professores participantes do curso, ainda 
não havia experimentado a realização de uma investigação estatística nos processos formativos anteriores em que já havia participado. Na sessão de formação onde foi realizada a investigação estatística, prontificou-se a realizar uma investigação com uma turma do Ensino Básico, optando por desenvolver investigação com a sua turma do $8 .^{\circ}$ ano. $\mathrm{Na}$ sessão onde compartilhou a sua experiência, justificou: "os alunos tinham muitas dificuldades e a turma era muito cheia, mas decidi fazer com eles porque apesar de tudo, eles ficam muito empolgados com coisas novas" (Sessão de formação).

Apesar de enfrentar obstáculos, tais como a quantidade de alunos em sala e as dificuldades de aprendizagem, Cláudia fez a sua primeira experiência em sala de aula a partir da necessidade de motivação dos seus alunos. Assim, decidiu que os próprios alunos deveriam escolher o tema da investigação e, consequentemente, colocar a questão a ser investigada:

Os meus alunos do $8 .^{\circ}$ ano decidiram investigar informações sobre a própria turma, investigando a idade de cada aluno da turma. Empolgados com algumas festas de 15 anos que aconteceriam nos próximos dias, queriam saber se ainda haveria alguma menina a fazer aniversário ainda esse ano. Para evitar tumulto, os alunos elegeram um representante para ir ao quadro e auxiliaram na observação e coleta dos dados, organizando uma tabela no quadro. (Relatório de investigação)

No momento da recolha de dados, Cláudia não fez uma modificação específica no que se refere à organização da turma. Os alunos permaneceram em seus lugares, e apenas um aluno, eleito pela turma, foi ao quadro para escrever os dados numa tabela enquanto todos acompanhavam esta escrita.

A professora buscava privilegiar um assunto do interesse e do contexto dos alunos, dando autonomia para que eles próprios formulassem o tema da investigação. Entretanto, a sua reduzida interferência ocasionou uma exploração também reduzida dos conceitos estatísticos, de modo que a pergunta formulada não exigia uma grande articulação de conhecimentos importantes como a construção de gráficos e tabelas, além do estudo de medidas de tendência central.

A professora ainda referiu a necessidade de "não criar muito tumulto" no processo de coleta e organização dos dados. É patente que, num caso de uma turma com mais de 40 alunos, a gestão da sala de aula se tornou mais complexa. Entretanto, esta decisão ocasionou alguma inércia por parte da maioria dos alunos nestas etapas do ciclo investigativo, não promovendo as relações colaborativas que poderiam existir durante a realização da investigação.

Analisar os dados, interpretar e comunicar os resultados

De acordo com Cláudia, a análise e a interpretação foram feitas de modo coletivo, a partir de uma discussão conjunta de toda a turma:

Eles conversaram em um grande grupo e estudaram os números organizados na tabela que montaram. Com pouca interferência minha, eles verificaram a faixa etária em que se encontra a maior parte dos alunos, bem como as idades que indicam menos alunos. (Relatório de investigação)
No momento da discussão e interpretação dos resultados, Cláudia procurou privilegiar a comunicação dos alunos. Além disto, enfatizou a importância da reflexão em grupo. No entanto, a análise dos dados, bem como a interpretação dos resultados, recebeu um destaque reduzido. Este problema, na verdade, tem relação com todo o contexto da investigação, visto que o problema proposto exigiu o uso reduzido das ferramentas estatísticas. Posteriormente, a professora fez um balanço da atividade realizada:

A turma é muito grande e gosta de trabalhar em conjunto, o que pode dificultar um pouco o trabalho. Eu sei que dispus de menos tempo do que o ideal para a realização da atividade e construção de outros conceitos estatísticos, como média, moda, mediana. Faltou ainda a construção de um gráfico para melhor visualização das informações [...] Eu sempre tive medo de fazer essas atividades, mas virou uma bagunça organizada. (Sessão de formação)

Cláudia mostrou-se capaz de identificar falhas, especialmente no que diz respeito às aprendizagens estatísticas. Além disso, reforçou a importância de um trabalho mais amplo, assumindo ser necessário mais tempo para a realização de tarefas desta natureza. Justifica as lacunas existentes pelos desafios na gestão de sala de aula, visto que a realização de tarefas de investigação requer uma configuração de sala de aula diferente da usual.

No seu planejamento, a professora menciona a intenção em realizar uma atividade investigativa com o uso de tabelas, de modo que os alunos propusessem um tema a ser investigado que fizesse parte do seu contexto. Não menciona um trabalho mais completo no que se refere às diferentes etapas do ciclo investigativo. Também não se evidencia a forma como diferentes conceitos estatísticos poderiam ser explorados a partir desta investigação. A participação dos alunos na atividade tornou-se o elemento central da aula. A gestão em sala de aula, por questões logísticas, teve pouca mudança em relação à configuração tradicional, na qual a participação ativa do aluno é reduzida. A professora aponta o fato de ser uma tarefa diferente da habitual como um dos principais fatores motivacionais para os alunos, fazendo referência também à necessidade de incorporar, na investigação, um assunto do interesse dos alunos.

\subsection{Luísa}

\section{A professora}

Luísa é uma professora que tinha, no período do curso, 42 anos de idade. Inicialmente, fez o Curso Normal Médio, obtendo sua conclusão em 1993. Além disto, atuava no $1 .^{\circ}$ ciclo do Ensino Fundamental há 18 anos. Decidiu fazer a Licenciatura em Matemática por ter, desde sempre, maior preferência pela disciplina. Segundo a professora, o motivo da sua preferência são "os caminhos que a Matemática nos leva" (Relatório de investigação).

No decorrer da especialização, apresentava muito desejo de aprender, apesar de assumir a existência de algumas 
dificuldades com alguns conceitos estatísticos, como por exemplo o uso das medidas de dispersão. A discussão sobre a didática da Estatística era o seu principal interesse. Ou seja, o seu discurso, no que diz respeito à abordagem da Estatística no contexto escolar, era alinhado ao desenvolvimento da literacia estatística. No entanto, tal como Cláudia, Luísa nunca havia experimentado a realização de investigações estatísticas no decorrer da sua formação inicial. Afirmou que "a minha formação foi muito centrada em conteúdos, não tinha muita coisa de didática. Principalmente na Estatística, que eu aprendi tão pouco" (Sessão de formação). Na realização da investigação estatística na experiência de formação, afirmou que era importante levar este tipo de trabalho para a sala de aula, mas indicou também que precisava de mais domínio do assunto, assumindo que o conhecimento do conteúdo didático do professor deve ser forte.

Luísa também é uma professora experiente e muito dedicada naquilo que faz. Como participante da experiência de formação, sempre procurava trocar as suas experiências com os professores e mostrou-se muito entusiasmada com a ideia de realizar investigações estatísticas:

Eu já tenho essa visão de transformar os alunos em pessoas mais críticas e com essas atividades fiquei com essa visão mais forte ainda... Claro que não podemos deixar os conteúdos, mas eu tenho feito com que meus alunos enxerguem o mundo que os rodeia [...] Minha formação em Estatística não me deu base, então tinha receio de fazer essas atividades. (Sessão de formação)

É patente que a sua maior motivação estava em poder abordar assuntos do cotidiano dos alunos e torná-los mais críticos ao gerirem diferentes informações do cotidiano.

\section{Colocar a questão e recolher os dados}

Luísa, de acordo com o seu planejamento, apresentou uma prioridade que consistia em explorar, inicialmente, os conceitos de gráficos e tabelas, bem como a sua leitura e construção. De acordo com a professora, a exploração do conteúdo antes da realização da investigação era essencial. Para isto foram utilizadas as tarefas exploradas no manual dos alunos. Além disto, afirmou ter reunido alguns temas possíveis para a realização da investigação: "Depois da exploração da sequência dos conteúdos, eu apresentei a proposta... Coloquei em exposição a ideia de alguns temas: cardápio da merenda escolar; brincadeiras infantis e modalidades esportivas". (Relatório de investigação)

Tal como Cláudia, Luísa procurou motivar os seus alunos de forma que eles escolhessem o tema a ser trabalhado e, consequentemente, eles próprios pudessem colocar a questão de investigação. Entretanto, delimitou as possibilidades com temas que possibilitassem a realização do trabalho. De acordo com a professora, toda a escola estava envolvida com os jogos olímpicos que aconteceriam naquele período e, por este motivo, buscaram investigar sobre a estrutura física da escola para sediar o evento, de modo a aprofundarem um tema de grande relevância não apenas para a escola, mas também para a comunidade na qual a escola pertence - o saneamento básico:

$\mathrm{Eu}$ fiz com que eles entrassem num consenso para ver quais eram as necessidades da escola, mas também levantamos umas questões muito bacanas sobre saneamento básico. Então elaboramos um questionário que eles levaram para a casa e perguntaram sobre a água encanada porque no município em que eu trabalho isso é escasso. (Sessão de formação)

De acordo com a professora, o processo de recolha de dados teve a participação de todos os alunos da turma e também da comunidade escolar, pelo que as famílias dos alunos puderam responder ao questionário relacionado ao saneamento básico. A professora identificou esta atividade como uma forma de levantar questões sociais, com a associação dos conceitos estatísticos, de forma que os alunos aprofundem não só os conhecimentos do currículo, mas também articulem conhecimentos acerca do ambiente que os rodeia. Evidenciase aqui o seu interesse em utilizar os conceitos estatísticos dos seus alunos para desenvolver o senso crítico e a capacidade de lidar com as diferentes informações.

\section{Analisar os dados, interpretar e comunicar os resultados}

De acordo com Luísa, a análise dos dados e a interpretação dos resultados foram geridas, em sala de aula, com a intenção de valorizar o trabalho colaborativo entre os alunos: "como eram 30 alunos muito novinhos, eu preferi dividilos em cinco grupos de seis" (Relatório de investigação). A professora valorizou, em sua narrativa, os diferentes debates realizados pelos alunos. Os debates em questão não estavam limitados apenas ao uso dos gráficos e tabelas, mas também relacionados aos aspectos sociais. A criação dos questionários para a recolha dos dados bem como a utilização dos gráficos e tabelas para a análise dos dados decorreram de um processo ativo dos alunos. A professora afirmou:

Para fazerem a análise dos dados, eles precisaram usar as tabelas e gráficos que conheciam, como por exemplo o gráfico de barras [...] O mais bacana é que com a análise dos dados eles vieram com críticas bem produtivas, com perguntas [...] Quando [estes problemas] seriam solucionados? Os alunos apresentaram os resultados numa culminância na escola, falaram sobre o aquífero do município, colocaram quantas pessoas têm água encanada. (Sessão de formação)

Luísa relacionou a investigação a um processo cíclico, no qual, de acordo com a resposta

a algumas perguntas, outras questões podem ser levantadas. Além disso, mencionou a necessidade de divulgar os resultados para a comunidade, já que o tema tem grande relevância. Ou seja, para a professora, o ciclo investigativo tem também papel importante na construção da cidadania.

$\mathrm{Na}$ apreciação da realização da investigação, Luísa mostrou a consciência do papel da investigação estatística no envolvimento dos seus alunos e foi capaz de sinalizar os problemas inerentes à atividade:

Os alunos assumiram um papel ativo durante as várias etapas do ciclo investigativo. No entanto, nas construções de seus gráficos, houve a necessidade da minha orientação. Mesmo com as informações em mãos eles sentiram um pouco de 
dificuldade na escolha do gráfico adequado para exposição do trabalho. (Relatório de investigação)

No que diz respeito à comunicação dos resultados para a comunidade escolar, a professora afirmou: "na hora da apresentação, houve um certo tipo de timidez, mas com o envolvimento da turma isso foi superado" (Relatório de investigação). No momento em que a turma apresentou maior dificuldade, a professora referiu o envolvimento dos alunos como o principal elemento para ultrapassar esta dificuldade.

No que se relaciona ao planejamento, Luísa buscou contemplar as diferentes fases do ciclo investigativo. A decisão do tema a ser investigado e também a organização, análise e interpretação dos resultados seriam realizadas em grupo. A recolha dos dados seria feita individualmente. O planejamento também contemplava a escolha de um tema que facilitasse a exploração de diferentes tabelas e gráficos, além de procurar motivar os alunos valorizando os seus interesses e contexto social. A professora mencionou, ainda, em seu planejamento a necessidade de explorar o senso crítico dos alunos. A gestão de sala de aula ocorreu conforme o seu planejamento, sendo a comunicação dos alunos e o trabalho coletivo privilegiados.

\section{Conclusão}

A elaboração de um plano de ensino para uma ou mais aulas tem grande influência no envolvimento dos alunos na escola quando este envolvimento é visto como uma articulação entre a aprendizagem ativa do aluno e aspectos motivacionais (Barkley, 2010). Deste modo, para além da intenção de manter os alunos entusiasmados com a atividade proposta, é necessário ter em atenção os aspetos cognitivos a serem alcançados. Neste sentido, o trabalho realizado por Cláudia corresponde a uma exploração reduzida dos conceitos e representações estatísticas, bem como do ciclo investigativo. Luísa fez menção aos conceitos e representações estatísticas a serem abordados e estabeleceu uma relação entre o ciclo investigativo e o desenvolvimento da literacia estatística de modo a explorar o senso crítico dos alunos (Franklin el al., 2005).

A gestão de sala de aula também tem um papel fundamental no envolvimento dos alunos na escola. As professoras utilizaram diferentes estratégias para conduzir o ciclo investigativo, e a organização estabelecida procurou atingir diferentes objetivos. A investigação estatística possui um caráter exploratório, no qual o aluno assume um papel ativo enquanto consolida as suas aprendizagens. Esta percepção é patente na prática de Luísa, que estimula a ação de todos os alunos ao promover trabalhos coletivos e individuais. Cláudia, por sua vez, limitou a movimentação dos alunos, tendo a sua preocupação com a vertente comportamental limitado a exploração da vertente cognitiva (Cothran \& Ennis, 2000).

O ensino dos conceitos estatísticos tende a ser realizado pela maior parte dos professores com destaque na aprendizagem dos conteúdos. Neste estudo, em ambos os casos, a realização de uma investigação estatística levou as professoras a perceberem outros aspectos relacionados ao processo de aprendizagem, sendo a motivação um elemento essencial no envolvimento dos alunos na investigação. Assim, as professoras evidenciaram uma associação da motivação aos interesses pessoais e sociais dos alunos. Ao permitirem que os próprios alunos escolhessem o tema a ser investigado, as professoras buscaram promover o seu envolvimento com a tarefa desde a sua fase inicial. Entretanto, é necessário haver um equilíbrio neste processo para que as escolhas sejam feitas de forma coerente e propiciadoras de uma aprendizagem ativa dos conteúdos estatísticos. A falta de orientação, como se verificou com Cláudia, pode resultar numa atividade que não contemple conteúdos que poderiam ser trabalhados, bem como algumas das etapas do ciclo investigativo.

As dificuldades das professoras relacionadas com a condução das etapas do ciclo investigativo podem resultar da reduzida experiência em desenvolver atividades desta natureza tanto na sua formação inicial quanto em suas práticas profissionais. $\mathrm{O}$ ciclo investigativo deve ser inserido nos processos formativos dos professores para o ensino da Estatística, de forma que estes possam desenvolver os seus conhecimentos do conteúdo e didático neste sentido e, consequentemente, estejam aptos a conduzir este tipo de atividade em sala de aula (Heaton \& Mickelson, 2002).

Finalmente, salientamos a importância da criação de processos formativos que tragam como elementos centrais os temas relativos ao envolvimento dos alunos na escola, que, como verificamos neste estudo, foram bem acolhidos pelas professoras. A associação deste processo formativo a situações autênticas de prática letiva (Smith, 2001) mostrou-se essencial para que os professores possam refletir sobre os desafios inerentes à realização da atividade proposta, incluindo o modo de enfrentar problemas, como a quantidade excessiva de alunos em sala, que é uma realidade frequente no Brasil.

\section{Referências}

Bahia, S., Veiga, F., \& Galvão, D. (2014). Creative climate and engagement of students in school: How do they relate? In F. Veiga. (Coord.) (2014). Envolvimento dos Alunos na Escola: Perspetivas Internacionais da Psicologia e Educação/ Students' Engagement in School: International Perspectives of Psychology and Education. Lisboa: Instituto de Educação da Universidade de Lisboa.

Barkley, E. (2010). Student engagement techniques: A handbook of college faculty. S. Francisco, CA: Wiley.

Bogdan, R., \& Biklen, S. (1994). Investigação qualitativa em educação. Porto: Porto.

Burrill, G., \& Biehler, R. (2011). Fundamental statistical ideas in the school curriculum and in training teachers. In C. Batanero, G. Burrill \& C. Reading (Eds.), Teaching statistics in school mathematics: Challenges for teaching and teacher education (pp. 57-69). NewYork, NY: Springer.

Cothran, D. J., \& Ennis, C. D. (2000). Building bridges to student engagement: Communicating respect and care for students in urban high schools. Journal of Research and Development in 
Education, 23, 106-117.

Franklin, C., Kader, G., Mewborn, D., Moreno, J., Peck, R., Perry, M., et al. (2005). Guidelines for assessment and instruction in statistics education (GAISE) Report. Alexandria, VA: American Statistical Association.

Friel, S. N., Bright, G. W., Frierson, D., \& Kader, G. D. (1997). A framework for assessing knowledge and learning in statistics (K-8). In I. Gal \& J. B. Garfield (Eds.), The assessment challenge in statistics education (pp. 55-63), Amsterdam, IOS Press.

Heaton, R. M., \& Mickelson, W. T. (2002). The learning and teaching of statistical investigation in teaching and teacher education. Journal of Mathematics Teacher Education, 5(1), 35-59.

Hipkins, R. (2012). The engaging nature of teaching for competency development. In S. L. Christenson, A. L. Reschly, \& C. Wylie (Eds.), Handbook of research on student engagement (pp. 441-456). New York: Springer.

Kader, G., \& Perry, M. (1994). Learning statistics with technology. Mathematics Teaching in the Middle School, 1(2), 130-136.

Makar, K., \& Rubin, A. (2007, July). Beyond the bar graph: Primary teachers' uses of informal inference to teach statistical inquiry. Paper presented at Fifth International Research Forum on Statistical Reasoning, Thinking, and Literacy (SRTL-5), University of Warwick, UK.

Martins, M. E. G., \& Ponte, J. P. (2007). Organização e tratamento de dados. Lisboa: DGIDC.
Ponte, J. P. (2005). Gestão curricular em Matemática. In GTI (Ed.), O professor e o desenvolvimento curricular (pp. 1134). Lisboa: APM.

Ponte, J. P. (2011). Preparing teachers to meet the challenges of statistics education. In C. Batanero, G. Burrill \& C. Reading (Eds.), Teaching statistics in school mathematics: Challenges for teaching and teacher education (pp. 299-309). New York, NY: Springer.

Ponte, J. P., Quaresma, M., Mata-Pereira, J., \& Baptista, M. (2015). Exercícios, problemas e explorações: Perspetivas de professoras num estudo de aula. Quadrante, 24(2), 11-134.

Posner, G., \& Rudnitsky, A. (2006). Course design: A guide to curriculum development for teachers. Boston: Allyn \& Bacon.

Skinner, E. A., \& Pitzer, R. (2012). Developmental dynamics of student engagement, coping, and everyday resilience. In S. L. Christenson, A. L. Reschly \& C. A. Wylie (Eds.), The handbook of research on student engagement (pp. 21-44). New York, NY: Springer Science.

Smith, M. S. (2001). Practice-based professional development for teachers of mathematics. Reston, VA: NCTM.

Veiga, F. H., Festas, I., Taveira, C., Galvão, D., Janeiro, I., Conboy, J., Carvalho, C., Caldeira, S., Melo, M., Pereira, T., Almeida, A., Bahía, S., \& Nogueira, J. (2012). Envolvimento dos alunos na escola: Conceito e relação com o desempenho académico: Sua importância na formação de professores. Revista Portuguesa de Pedagogia, 46(2), 31-47. 